\title{
Big Five Personality Traits and Outcomes for First-Year College Students
}

\author{
John W. Lounsbury, Jacob J. Levy, Richard A. Saudargas, and Lucy W. Gibson
}

Based on a sample of 1,834 undergraduates, the Big Five personality traits of Agreeableness, Conscientiousness, Emotional Stability, Extraversion, and Openness were found to be significantly but differentially related to seven outcome variables: life satisfaction, college satisfaction, GPA, Sense of Identity, intention to withdraw from school, graduate school plans, and recommending the school to others. Results were discussed in terms of theoretical and practical implications. It was suggested that personality traits may be considered by organizations and personnel who work with students in the process of transition from high school to college and during orientation programs, among others.

The purpose of this article is to examine the relationships between the Big Five personality traits and important outcomes for first-year college students. Recent developments in personality research are first discussed with emphasis on their relevance for college student behavior.

Prior to the 1990s, most research on personality was fragmented, non-cumulative, and piecemeal owing to the lack of parsimonious and widely accepted models. There were so many different traits that it was difficult to make comparisons and generalizations. For example, with regard to college student behavior, two compendia of research on the impact of college on students (Feldman \& Newcomb, 1969; Pascarella \& Terenzini, 2005) list over 100 different relevant personality characteristics, including such diverse traits as abasement, achievement motivation, allocentrism, anxiety, authoritarianism, autonomy, deference, dependability, dominance, emotionality, flexibility, friendliness, identity achievement, impulsivity, integrity, intraceptiveness, locus of control, modesty, neatness, nurturance, openness to change, orderliness, persistence, planfulness, quietness, self-esteem, self-confidence, social extroversion, thinking introversion, and venturesomeness.

The dilemma of too many traits was resolved with the advent, development, and extensive validation of what has come to be known as the Big Five model of personality (De Raad, 2000). The Big Five model posits that all normal personalities can be represented by five basic personality traits that encompass behavior in many different domains of experience regardless of age, gender, ethnicity, or culture. Many subsequent

John W. Lounsbury (jlounsbury@aol.com) and Richard A. Saudargas (rsaudarg@bellsouth.net) are professors, and Jacob J. Levy (Jacob.levy@comcast.net) is an assistant professor, all in the Department of Psychology at the University of Tennessee, Knoxville. Lucy W. Gibson (lwgibson47@aol.com) is the vice president at Resource Associates, Inc. 
empirical studies have verified the reliability and validity of the Big Five constructs of Openness, Conscientiousness, Extraversion, Agreeableness, and Emotional Stability (De Raad, 2000). The Big Five traits have also been found to be related to a variety of important criterion variables, such as job performance (Barrick \& Mount, 1991), absenteeism (Judge, Martocchio, \& Thoresen, 1997), accidents (Salgado, 1997), and life satisfaction (DeNeve \& Cooper, 1998), and, in academic settings, to academic performance (Lounsbury, Gibson, Sundstrom, Wilburn, \& Loveland, 2003), absenteeism (Lounsbury, Steel, Loveland, \& Gibson, 2004), and satisfaction with college (Lounsbury, Saudargas, Gibson, \& Leong, 2005).

In the present study, we examined the relationship between the Big Five traits and seven different outcome variables for college freshmen. Given the importance of college student satisfaction as a criterion variable in higher education (e.g., Astin, 1997), we measured overall life satisfaction and satisfaction with the college attended. We also measured one of the most frequently studied indicators of academic performance-grade point average (GPA). In view of its importance as an indicator of student withdrawal (Lounsbury, Saudargas, \& Gibson, 2004), we also assessed the student's intention to withdraw from school and plans to pursue graduate study. We also asked students if they would recommend the college they are attending to other students and, finally, following Chickering and Reisser's (1993) emphasis on identity as a key outcome of college student development, we measured students' identity achievement. In view of the nature of the Big Five traits and prior research (De Raad, 2000; Lounsbury et al., 2005), we expected to find positive relationships in all cases, except withdrawal intention, which we expected to be negatively related to the Big Five traits. After presenting the results for these relationships, we discuss potential applications of the Big Five traits in the college student transition process.

\section{Method}

\section{Participants}

The sample for the present study included 1,602 students enrolled in a First-Year Studies program and 232 freshmen students in an introductory psychology course at a large, public Southeastern U.S. state university. Of the total sample, $68 \%$ were female (32\% male); $82 \%$ were Caucasian; $12 \%$ African American; $2 \%$ Hispanic; $2 \%$ Asian; and $2 \%$ other. Eighty-eight percent of the participants were in the 18-19 year-old age group; $12 \%$ were $20-21$; and $6 \%$ were over 21 .

\section{Procedure}

After obtaining human subjects approval from the university's Institutional Review Board, participants were solicited to take a personality inventory online. Upon completion, participants were provided a feedback report summarizing their personality characteristics and implications, including area of study, major, social life, managing 
stress, study habits, living situation, and using campus resources. Students in the introductory psychology course were offered extra credit for participation.

\section{Measures}

Personality. The personality measure used in this study was the Resource Associates Transition to College (TTC) inventory, a normal personality inventory contextualized for college students from an adolescent personality inventory that has been used for adolescents from middle school through high school and college. Scale development, norming, reliability, criterion-related validity, and construct validity information for this personality inventory can be found in Lounsbury, Gibson, et al. (2003); Lounsbury, et al. (2004); and Lounsbury, Sundstrom, Loveland, and Gibson (2003). For each item on the TTC, respondents expressed agreement or disagreement on a five-point Likert scale (1=Strongly Disagree; 2= Disagree; 3=Neutral/Undecided; 4=Agree; 5=Strongly Agree). Brief descriptions of the Big Five personality traits and the Sense of Identity scale measured by the TTC inventory are given below:

Agreeableness - being equable, participative, helpful, cooperative, and inclined to interact with others harmoniously.

Conscientiousness — being reliable, trustworthy, dependable, orderly, and rulefollowing.

Emotional Stability — overall level of adjustment and emotional resilience in the face of stress and pressure.

Extraversion-tendency to be sociable, outgoing, gregarious, warmhearted, expressive, and talkative.

Openness - receptivity and openness to change, innovation, new experience, and learning.

Sense of Identity - Knowing one's self and where one is headed in life, having a core set of beliefs and values that guide decisions and actions; and having a sense of purpose.

Satisfaction. We used Lounsbury et al.'s (2005) General Life Satisfaction and College Satisfaction scales, which is a set of 22 items used to measure satisfaction with life in general and satisfaction with the college. Fifteen General Life Satisfaction items asked respondents to rate their satisfaction with "yourself," "How much fun you are having," "the place where you live," "health and physical condition," "financial situation," "friendships," "your love life," "social life as a whole," "safety and security," "your level of personal maturity," "job" (if applicable), "prospects for the future," and "your life as a whole." Seven College Satisfaction items asked respondents how satisfied they were with "how much you are learning in school," "your rate of progress toward a college degree," "the availability of courses you want or need," "the general quality of professors you have taken courses from," "the availability and quality of academic advisers," "your academic major," and "your GPA." Responses for the satisfaction items were made on a 7-point Likert scale: $1=$ Very Dissatisfied, $2=$ Dissatisfied, 3 = Slightly Dissatisfied, 4 = Neutral, $5=$ Slightly Satisfied, $6=$ Satisfied, $7=$ Very 
Satisfied.

The online questionnaire also contained demographic questions pertaining to age, sex, race/ethnicity, year in school, grade point average (GPA), and future intentions.

\section{Results}

Presented in Table 1 are the correlations between the Big Five traits and the outcome variables. All but three of the 35 correlations were statistically significant, with generally higher magnitude correlations observed between the Big Five traits and Life Satisfaction, especially Emotional Stability $(r=.54, p<.01)$ and Extraversion $(r=.46$, $p<.01)$ and for Sense of Identity, especially Emotional Stability $(r=.54, p<.01)$ and Agreeableness $(r=.33, p<.01)$. For the other variables, the largest magnitude correlations were observed between Conscientiousness and GPA $(r=.33, p<.01)$, Openness and planning to pursue graduate study $(r=.32, p<.01)$, Emotional Stability and intention to withdraw from school $(r=-.35, p<.01)$, and Extraversion and willingness to recommend to other people the college the student is attending.

\section{Discussion}

The present results indicate that the Big Five traits are extensively related to important outcomes for first-year college students, including satisfaction with the college and global life satisfaction, GPA, a sense of identity, and intention to withdraw from school, intention to pursue graduate study, and recommending the college attended to other people. Taken as a whole, the present findings not only affirm the robustness of the Big Five traits (e.g., De Raad, 2000), but also indicate their extensive validity in the college student context. Moreover, our results provide support for prior findings concerning the relationship between Conscientiousness and academic performance (e.g., Chamorro-Premuzic \& Furnham, 2003) and Emotional Stability and student satisfaction (e.g., Lounsbury, Saudargas, et al., 2005). The latter results are consistent with similar findings for Conscientiousness and job performance (Barrick \& Mount, 1991), and Emotional Stability and job and career satisfaction (Lounsbury, et al., 2003). The present results also support Chickering and Reisser's (1993) contention that college student identity has multiple linkages to the personal attributes of college students. In fact, four of the Big Five traits correspond to several of Chickering's key developmental vectors: managing emotions is related to Emotional Stability; moving through autonomy toward interdependence is related to Conscientiousness, and developing mature interpersonal relationships is conceptually similar to Extraversion and Agreeableness. Interestingly, no one trait is consistently most strongly related to these outcomes; therefore, we would recommend that any usage of Big Five measures by college student personnel include all five traits.

There are a number of potential practical applications associated with using Big Five trait information to help students successfully negotiate the transition to college. Most of these revolve around two concepts: (1) maximizing person-environment fit for students; 
and (2) enabling college student personnel who work with students to adjust their approach to students to enhance their own effectiveness. Each of these will be discussed below.

First, the underlying rationale for person-environment fit is that people, in this case first-year college students, are more satisfied with, productive in, and committed to environments that are consonant with their personality (including needs, interests, values, preferences, and characteristic ways of behaving). A concern for optimizing personenvironment fit is an important component of many different functions and programs for students (Hamrick, Evans, \& Schuh, 2002), including orientation, advising, choosing a major and participating in activities and classes specific to a given major, learning communities, roommate assignments, career planning, and membership in sororities and fraternities, and service organizations. Indeed, we contend that personality information can be potentially useful in every situation in college where the student makes a choice about membership, participation, level of involvement, and psychological investment, which can include choices concerning: type of residence, roommate, adviser, major, electives, course load, course format, clubs and voluntary student organizations, leisure and recreation activities, study habits, social activities, dating and intimate relationships, degree pacing, career planning, internships, employment, and study abroad programs, among others. Better student-college environment fit can be facilitated by knowing more about the student's key personality traits, where this knowledge is acquired either by the student (e.g., by taking a personality inventory) or person working with the student, such as an academic adviser, or both.

Because many of these same findings have also been validated for high school students (Lounsbury, Gibson, et al, 2003; Lounsbury, Steel, et al., 2004; Lounsbury, Tatum, Gibson, Park, Sundstrom, Hamrick, \& Wilburn, 2003), it should be feasible for organizations and personnel who focus on the transition to college and college student orientation to try using these findings for tailoring programs to students. As noted by Pascarella and Terenzini (1991), the transition from high school to college represents a major change for students and "orientation programs serve an important early socialization function" (p. 659). We suggest that the personality traits of students should be taken into account by any personnel who work with students since these traits will likely shape how the student behaves during orientation and transition and how students will respond to different interventions either as predictor, mediator, or moderator variables (Matthews, Deary, \& Whiteman, 2003).

Although more formal methods are available for classifying the psychological structure of different environments (Moos, 1996), selecting appropriate environments can be achieved by logic and common sense. For example, students scoring lower on Conscientiousness might be advised to avoid structured courses emphasizing conformity and standardization, and to choose more dynamic courses that encourage creative self-expression and innovative thinking. Also, students with higher levels of Extraversion might be advised to take courses involving classroom discussion and personal presentations. Or, a student scoring very low on Emotional Stability may be encouraged to seek services at their college/university counseling center to assist in 
developing appropriate strategies for coping with college adjustment issues and/or managing stress.

Because the Big Five traits are positively related to so many desirable outcomes, an alternative to trying to maximize outcomes through better student-environment fit would be to develop programs and activities that are designed to increase the trait level itself for students. Some examples are: Agreeableness - civility training and team-building exercises such as ropes courses; Conscientiousness - time management and study skills training programs; Emotional Stability—stress management workshops and individual counseling; Extraversion-student mixers, joining social or service organizations, including, but not limited to Greek life or pre-professional organizations; and Openness-diversity training, cultural events, and study abroad programs.

Another way that information about students' personality traits can be useful is when the person working with the student adjusts his or her style to fit the trait level of the student. For example, when dealing with more introverted students, advisers can use written communication; e-mail; and a formal, low-key presentation style, whereas they can employ face-to-face interactions; direct, personal questions; and informal giveand-take when interacting with more extroverted students. Or, when working with highly conscientious students, an adviser can present information in a logical, structured manner, clarify policies and expectations, set goals, and help the student create a comprehensive plan of study. In this vein, there are complete systems of instruction based on designing instructional methods and learning procedures to match the personality characteristics of students (e.g., Jonassen \& Grabowski, 1993).

Given the importance of personality traits in college student learning, adjustment, and development, it should come as no surprise for some college student personnel to learn that personality trait information is already being used in a broad range of programs and activities, including: admissions (Allik \& Realo, 1997), extended orientation courses (Buhr, Pelletier, \& Wark, 1987), academic advising (Crockett \& Crawford, 1989), student leadership development (Posner \& Brodsky, 1992), residence hall placement and roommate assignments (Fuller \& Hall, 1996). In the future, we expect to see increased usage of personality traits, particularly the Big Five, to customize and tailor many different programs for students in the first year of college and in the transitional interval between high school and college. Such programs would serve prevention-intervention functions that would benefit both the student and college.

\section{Limitations}

There are several limitations of the current study which should be noted. A single public, university in the Southeastern United States served as the study site; therefore, the generalizability of the present results to colleges and universities in different geographic locations and contexts is unknown. Also, GPA was measured via self-report, rather than through objective records. While intention to withdraw from school is an interesting measure, it is not the same thing as actual withdrawal, so we do not know if the current findings would be generalizable to withdrawal/retention as measured using 
registration records. In addition, the seven items relating to campus-specific satisfaction did not assess other domains of college experience, such as peer relations, involvement in campus organizations, student health, access to technological resources (i.e., computers labs), sense of community on campus, type of living environment, sociocultural makeup of the student body, class size, and financial assistance, among others.

Nevertheless, the results of the present study indicate that personality traits are significantly related to several important outcomes for first-year college students. Future research can confirm these findings, extend them to a broader range of outcomes, and further elaborate policy and program implications for the field of college student administration and development.

\section{References}

Allik, J., \& Realo, A. (1997). Intelligence, academic abilities, and personality. Personality and Individual Differences, 23, 809-814.

Astin, Alexander W. (1977). What matters in college?: Four critical years revisited. San Francisco: Jossey-Bass.

Barrick, M. R., \& Mount, M. K. (1991). The big five personality dimensions and job performance: A meta-analysis. Personnel Psychology, 44, 1-26.

Buhr, T., Pelletier, G., \& Wark, D. (1987). An orientation program that increases the quality of student-adviser contact. Journal of College Student Personnel, 28, 462-463.

Chamorro-Premuzic, T., \& Furnham, A. (2003). Personality predicts academic performance: Evidence from two longitudinal university samples. Journal of Research in Personality, 37, 319-338.

Chickering, A.W., \& Reisser, L. (1993). Education and identity (2nd ed.). San Francisco: Jossey-Bass.

Crockett, J. B., \& Crawford, R. L. (1989) The relationship between Myers-Briggs Type Indicator (MBTI) scale scores and advising style preferences of college freshmen. Journal of College Student Development, 30, 154-161.

De Raad, B. (2000). The Big Five personality factors: The psycholexical approach to personality. Seattle: Hogrefe \& Huber.

DeNeve, K. M., \& Cooper, H. (1998). The happy personality: A meta-analysis of 137 personality traits and subjective well-being. Psychological Bulletin, 124, 197-229.

Feldman, K. M., \& Newcomb, T. M. (1970). The impact of college on students, Volume I. San Francisco: Jossey-Bass.

Fuller, B. E., \& Hall, F. J. (1996). Differences in personality type and roommate compatibility as predictors of roommate conflict. Journal of College Student Development, 37, 510-518.

Hamrick, F. A., Evans, N. J., \& Schuh, J. H. (2002). Foundations of student affairs practice: How philosophy, theory, and research strengthen educational outcomes. San Francisco: Jossey-Bass. 
Jonassen, D. H. \& Grabowski, B. L. (1993). Handbook of individual differences, learning, and instruction. Hillsdale, NJ: Lawrence Erlbaum.

Judge, T. A., Martocchio, J. J., \& Thoresen, C. J. (1997). Five-factor model of personality and employee absence. Journal of Applied Psychology, 82, 745-755.

Lounsbury, J. W., Gibson, L. W., Sundstrom, E., Wilburn, D., \& Loveland, J. (2004). An empirical investigation of the proposition that "School Is Work." A comparison of personality-performance correlations in school and work settings. Journal of Education and Work, 17, 119-131.

Lounsbury, J. W., Saudargas, R. A., \& Gibson L. W. (2004). An investigation of Big Five and narrow personality traits in relation to intention to withdraw from college. Journal of College Student Development, 45, 517-534.

Lounsbury J. W., Saudargas, R. A., Gibson, L. W., \& Leong, F. T. (2005). An investigation of broad and narrow personality traits in relation to general and domain-specific life satisfaction of college students. Research in Higher Education, 46, 707-729.

Lounsbury, J. W., Steel, R. P., Loveland, J. M., \& Gibson, L. W. (2004). An investigation of personality traits in relation to adolescent school absenteeism. Journal of Youth and Adolescence, 33, 457-466.

Lounsbury, J. W., Sundstrom, E., Loveland, J. M. , \& Gibson, L W. (2003). Intelligence, "Big Five" personality traits, and work drive as predictors of course grade.

Personality and Individual Differences, 35, 1231-1239.

Lounsbury, J. W., Tatum, H., Gibson, L. W., Park, S. H., Sundstrom, E. D., Hamrick, F. L.,\& Wilburn, D. (2003). The development of a Big Five adolescent personality scale. Psychoeducational Assessment, 21, 111-133.

Matthews, G., Deary, I. J., \& Whiteman, M. C. (2003). Personality traits (2nd ed.). Cambridge: Cambridge University Press.

Moos, R. H. (1996). Understanding environments: The key to improving social processes and program outcomes. American Journal of Community Psychology, 24(1), 193201.

Pascarella, E. T., \& Terenzini, P. T. (1991). How college affects students: Findings and insights from twenty years of research. San Francisco: Jossey-Bass.

Pascarella, E. T., \& Terenzini, P. T. (2005). How college affects students: A third decade of research. San Francisco: Jossey-Bass.

Posner, B. Z., \& Brodsky, B. (1992). A leadership development instrument for college students. Journal of College Student Development, 33, 231-237.

Salgado, J. F. (1997). The five factor model of personality and job performance in the European community. Journal of Applied Psychology, 82, 30-43. 


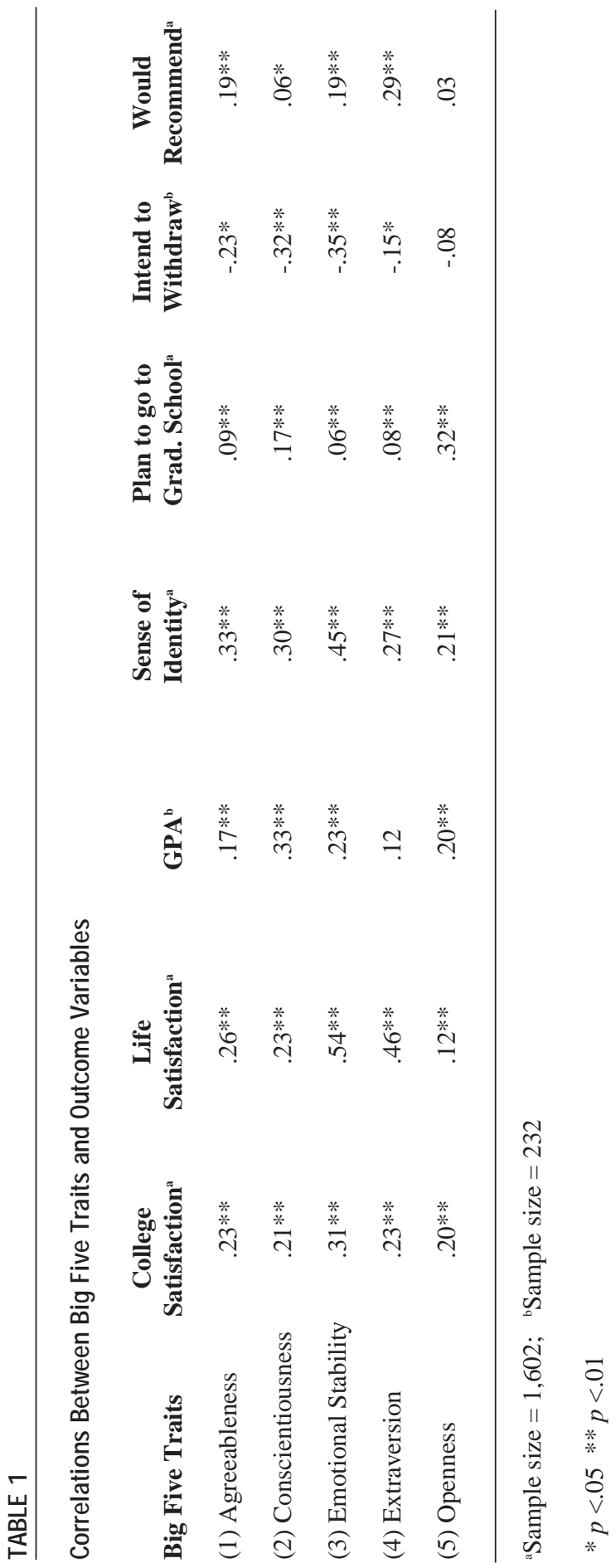

